\title{
André Bjerke og psykoanalysen
}

\author{
Etter noen innledende betraktninger om hvordan det er å være sønn av en betydelig kulturpersonlighet \\ omtales i artikkelen tre kriminalromaner som André Bjerke skrev under pseudonymet Bernhard Borge og \\ der detektivhelten er psykoanalytiker Kai Bugge: Nattmennesket (1941), De dødes tjern (1942) og Skjult mønster \\ (1950). Dernest belyses André Bjerkes forhold til psykoanalysen gjennom to essayer: Erindringer om fremtiden \\ (1953) og Arthur Koestler og radikalismen (1955).
}

\section{Espen Bjerke}

espen.bjerke@so-hf.no

Det å være sønn av en kjent forfatter og kulturpersonlighet som André Bjerke (1918-85) har jeg hatt et noe dobbelt forhold til: dels skamfull og sjenert, dels stolt. Etter hvert som jeg er blitt eldre har stoltheten fătt mer overtaket. Jeg føler mer og mer at jeg kan vedstå meg min far. Han døde for snart 30 år siden, men det rare er at han blir litt «udødelig» når han på en måte stadig er nærværende gjennom alt han skapte.

Han var jo en meget allsidig og produktiv forfatter som publiserte dikt for store og små, gjendiktninger av utenlandsk lyrikk og skuespill, en bok om sjakk, Spillet i mitt liv (1), som også var det nærmeste han kom en selvbiografi. Han skrev om Goethes fargelære og om språk m.m., var en ivrig debattant og skrev tallrike essayer og debattinnlegg, som også utkom i bokform. Han holdt en mengde foredrag og prologer, som også for en stor del finnes på trykk. I tillegg deltok han i TV- og radioprogrammer om sjakk, limericker, Goethes fargelære og okkultisme.

Jeg vil i denne artikkelen prøve å belyse André Bjerkes forhold til psykoanalysen slik dette fremgår av kriminalromanene han skrev under pseudonymet Bernhard Borge samt i noen senere essayer (2-6).

Jeg tror denne gjennomgangen vil vise at det skjedde en endring i hans forhold til psykoanalysen - fra stor entusiasme, da særlig knyttet til psykoanalysen som metode, til en gradvis økende skepsis, knyttet til psykoanalysen som livsanskuelse.

\section{Psykoanalytisk litteratur}

Blant hans etterlatte bøker finnes mye psykoanalytisk litteratur, bl.a. mesteparten av Sigmund Freuds (1856-1939) Gesammelte Schriften fra 1924-25. Her finnes førsteutgavene av Ernest Jones' (1879-1958) store Freud-biografi i tre bind: Sigmund Freud: life and work. På norsk finner jeg
Forelcesninger til indførelse i psykoanalyse fra 1929 og Nytt i psykoanalysen fra 1934 begge oversatt av den senere Hamar-biskop Kristian Schjelderup.

Det finnes en solid stripe med Carl Gustav Jungs (1875-1961) bøker, bl.a. en førsteutgave av Psychologische Typen fra 1921. Så vidt jeg kan se blir det henvist lite til Jung i André Bjerkes forfatterskap. Dette er litt forbausende, siden Jung, med sin sans for arketyper og metafysikk, hadde en høyere stjerne enn Freud i de antroposofiske kretser der Bjerke ofte vanket.

En annen av pionerene var han imidlertid sterkt opptatt av, nemlig Wilhelm Stekel (1868-1940). Jeg husker han hadde Stekels

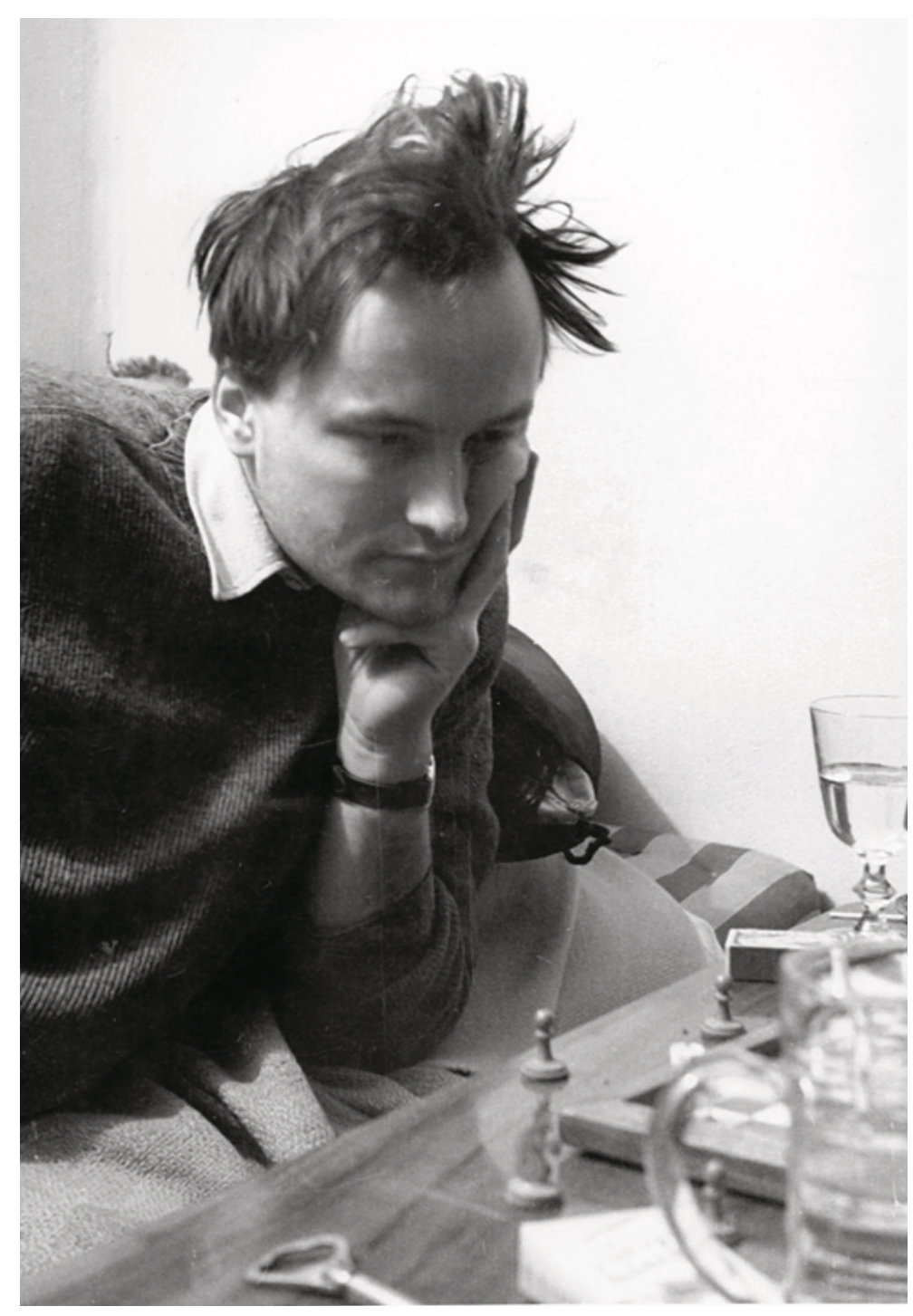

André Bjerke ved sjakkbrettet, 1946. Foto privat 


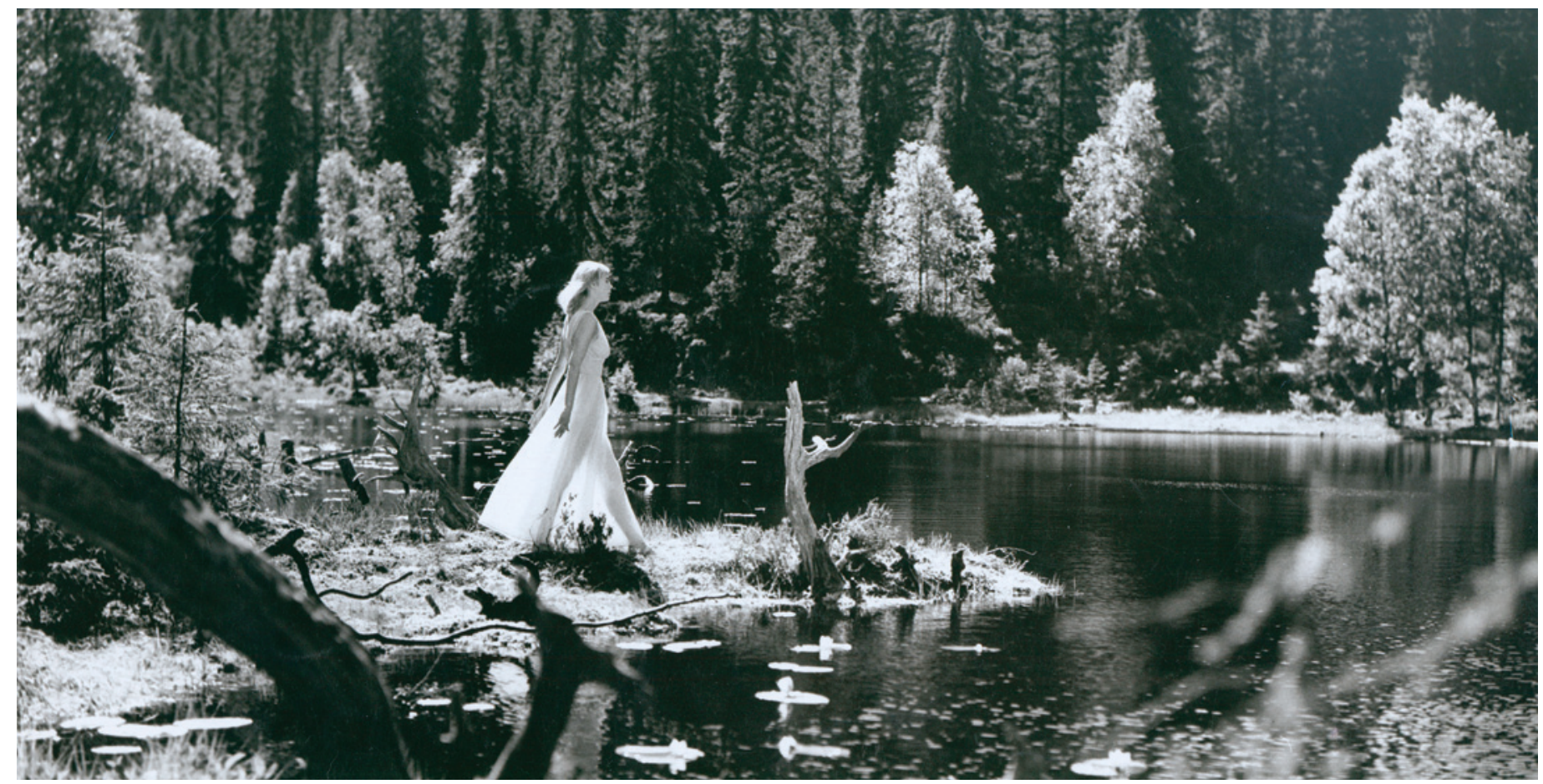

Fra filmen De dødes tjern, 1958. Foto Nasjonalbiblioteket. Gjengitt med tillatelse av Storyline

samlede verker i bokhyllen, men disse er dessverre forsvunnet. Stekel var bl.a. kjent for sine litt vidløftige, men begavede drømmetydninger, noe Freud dels ga ham kreditt for, også etter bruddet som fulgte etter Stekels forskjellige avvik fra «den rette lære».

Som en kuriositet kan nevnes et uinnbundet eksemplar av Die Bione av Wilhelm Reich (1897-1957), utgitt på Sexpol Forlag i 1938. Reich satte jo spor etter seg i Norge, der han oppholdt seg store deler av 1930årene, og han blir fortsatt verdsatt for sine bidrag innen karakteranalyse og vegetoterapi.

\section{Kriminalromanene}

André Bjerke skrev fire kriminalromaner under pseudonymet Bernhard Borge: Nattmennesket, som utkom i 1941, De dødes tjern fra 1942, Døde menn går i land fra 1947 og Skjult mønster fra 1950 (1-3, 7). Disse bøkene kommer i stadig nye opplag og leses fortsatt av mange. De er også oversatt til en rekke europeiske språk, bl.a. engelsk og tysk. Nattmennesket er også utgitt på japansk.

Tre av bøkene er «psykoanalytiske». Jeg refererer ganske utførlig fra disse for å anskueliggjøre hva som ble vektlagt innenfor psykoanalysen anno 1940-50, sett fra en intellektuell og entusiastisk psykoanalytisk interessert ung mann fra Oslo. Han var bare 22 år gammel da han skrev Nattmennesket.

I alle tre bøkene står ødipuskomplekset helt sentralt som forståelsesfaktor og bak- grunn for de forbrytelser som begås. Erotisk søskenkjærlighet og søskenhat, som forstås som avledninger av ødipuskomplekset, er gjennomgangstema. I Nattmennesket er det søstrene Eva og Sonja handlingen kretser rundt, mens deres avdøde mektige far ruver i bakgrunnen. I De dødes tjern er det søskenparet Bjørn W og Liljan, som har en sterk erotisk tiltrekning til hverandre, uten at vi her får vite noe om deres bakgrunn. I Skjult mønster er det forholdet mellom den 20-årige Irene og hennes vakre mor, Elisabeth C, som står i sentrum, med farens søster Signe og hennes sterke erotiske binding til sin bror som bakteppe.

\section{Kai Bugge}

Først en kort presentasjon av psykoanalytikeren Kai Bugge, som er hovedpersonen og detektivhelten i de to første bøkene. Han dukker ikke opp i Døde menn går i land, men entrer igjen scenen og rydder opp i en «vill» analyse mot slutten av Skjult mønster.

Fortelleren og jeg-personen Bernhard Borge beskriver i Nattmennesket Kai Bugge som en psykoanalytiker som nyter en voldsom popularitet blant byens fruer, særlig i de litt høstlige årsklasser, og at han etter hvert er blitt noe av en lokal guddom hvis menighet strekker seg fra Parkveien til Smestad, fra Drammensveien til Bislett stadion. Hans spesialområde er imidlertid forbrytelsens psykologi. Hans hovedverk Das Verbrechen als Erlösung ble beslaglagt og brent på den store autodafé for smusslitteratur i 1933.

Bugge beskrives som en mann i midten av 30-årene, slankt bygd og med noe slengete og gutteaktig i skikkelsen. Borge skriver at det utstråler en eiendommelig ro fra den late skikkelsen og at man ikke kan unngå å bli smittet av hans velvære. Han er en mann som går sine egne veier, noe Borge allid har beundret, siden han selv pleier å følge flertallet.

\section{Nattmennesket}

Nattmennesket utkom i 1941 (2). Den ytre rammen er som i en klassisk kriminalfortelling av Agatha Christie. Åtte unge mennesker, bl.a. jeg-personen Bernhard Borge, er på hyttetur ved sjøen. Eieren myrdes, de andre finner ham om morgenen med avskåret strupe. Alt tyder på at drapsmannen er en av hyttegjestene. Psykoanalytikeren Kai Bugge ankommer sammen med politiet og iverksetter sin egen etterforskning. Han finner en nesten ferdig løst kryssordoppgave. Bare tre relativt enkle ord er ikke funnet, og de kan alle assosieres med noe morderisk/ aggressivt.

Bugge redegjør for fortrengte komplekser og feilhandlinger. Han hevder at kryssordet er et skoleeksempel på fortrengning. Han beskriver fortrengning som en form for justis som menneskesjelen utøver overfor seg selv, rettet mot alt det som vårt moralske, bevisste jeg ikke kan anerkjenne - våre perverse og destruktive tilbøyeligheter. Det er 


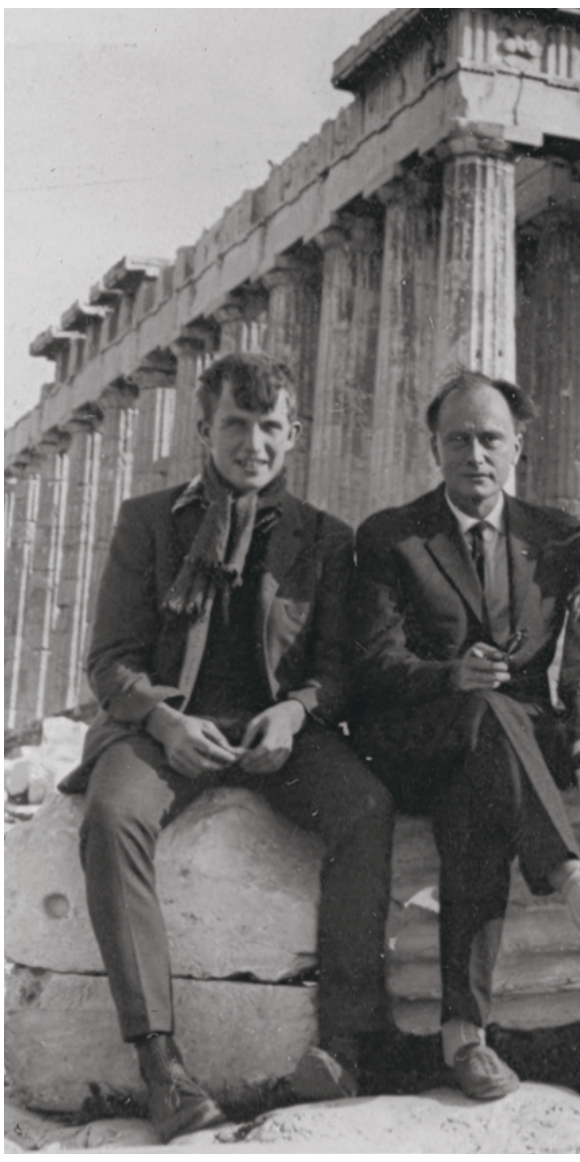

Far og sønn i Athen, 1966. Foto privat

ikke bare enkelte forbudte forestillinger som vi fortrenger, men også assosiasjoner til dem, hele komplekser av forestillinger blir fortrengt. Dette er med å bestemme hvilke ting vi ikke gjør og hvilke ord vi ikke finner $i$ en kryssordoppgave.

Mye tyder på at ugjerningen er begått av en sterkt psykisk forstyrret person. Litt ute i boken beskriver Bugge den spesielle type galskap som har gitt navn til den. Han hevder at man her står overfor det vi kan kalle et «nattmenneske», dvs. et menneske som beholder en tynn ferniss av normalitet så lenge det har dagslyset og våkne mennesker omkring seg, men som spontant slår om til sin egen motsetning i samme øyeblikk som mørket og ensomheten melder seg. Den skyldige har en slik dobbeltpersonlighet - om dagen den korrekte og sjarmerende dr. Jekyll, om natten mr. Hyde, uhyret, varulven.

Bugge løser etter hvert saken på grunnlag av sin psykoanalytiske forståelse av ødipalkonfliktens betydning, av hvordan fortrengt eller dissosiert fars- og søskenhat fører hovedpersonene i ulykken. Hans beskrivelse av «nattmennesket» passer vel med det vi dag ville kalle en variant av dissosiativ identitetsforstyrrelse. Som verktøy benytter han tolking av feilhandlinger og drømmetydning. Dessuten iverksetter han en nokså skruppelløs regi for å røyke ut morderen, noe som bringer flere av aktørene i livsfare og fører til at morderen selv tar livet av seg.

\section{De dødes tjern}

De dødes tjern utkom året etter, i 1942 (3). Dette er kanskje den mest kjente av Bernhard Borge-historiene, bl.a. fordi den ble filmet i 1958. Filmen blir med jevne mellomrom vist på TV og regnes som en av de mer vellykkede norske filmer fra denne tiden. Det blir hevdet at André Bjerke med Nattmennesket var den første som fullt ut lot psykoanalysen ligge til grunn for oppklaringen av et kriminalmysterium. I De dødes tjern kommer også det okkulte inn, som et nytt element.

Aktører i handlingen er, ved siden av krimforfatteren og jeg-personen Bernhard Borge, hans kone Sonja (som han giftet seg med etter Nattmennesket), psykoanalytikervennen Kai Bugge, søsknene Bjørn og Liljan Werner, hennes kjæreste Harald Gran og okkultistvennen Gabriel Mørk. (Sistnevnte ble gestaltet av André Bjerke i filmen fra 1958.)

Bjørn $\mathrm{W}$ reiser til sin nyinnkjøpte hytte på jakttur. Noe senere leser vennene $i$ avisen at han er forsvunnet. Ting tyder på at han har forsvunnet i Blåtjern eller «De dødes tjern», som det heter på folkemunne, etter et gammelt sagn om Tore Gruvik som druknet sin søster og seg selv i dette tjernet. Vennene samler seg og iverksetter en rask unnsetningsekspedisjon til Østerdalen.

Vi finner mange av de samme elementene som i Nattmennesket når det gjelder Bugges forståelse og oppklaringsmetode. Når jeg sier at De dødes tjern også har et okkult innslag, er det ikke spøkelseshistorien om Tore Gruvik jeg tenker på. Den analyseres etter hvert bort. Det nye og «okkulte» elementet er Bugges (og trolig Bjerkes) vektlegging av telepati som en realitet og av hvor virksomme telepatiske krefter kan være, spesielt under søvn. Dette er for så vidt i tråd med hva Freud hevdet, men er fortsatt et kontroversielt tema (eller et ikke-tema) innen psykoanalysen (8).

\section{Skjult mønster}

Skjult mønster, som kom i 1950, er den minst kjente av Bernhard Borge-bøkene, men samtidig den André Bjerke var mest fornøyd med som psykoanalytisk triller betraktet (4). Den ble meget godt mottatt av anmelderne. Forfatteren Tor Edvin Dahl (alias David Torjussen) lanserte den like godt som verdens beste kriminalroman i forordet til nyutgivelsen i Gyldendals Svarte serie i 1974 (9). Det kan være flere grunner til at denne boken allikevel er lite kjent. Den er relativt stillestående, det meste foregår på et indre plan. Og for første gang er Kai Bugge i forkant av begivenhetene og forhindrer et drap. Ja faktisk forekommer det ikke drap i boken i det hele tatt!

Mesteparten av handlingen fremkommer via psykologistudent Jørgens dagboknotater. Vi får gjennom disse vite hvilke overveielser Jørgen gjør seg om det å ta venninnen Irene i psykoanalytisk behandling. Freud selv hadde bestemt advart mot «vill» analyse, og Bugge hadde alltid hevdet at en dårlig analytiker gjør mer skade enn ti kloke koner. I det videre får vi så beskrevet hvordan Jørgen starter helt etter boken, men etter hvert blir fanget i sine motoverføringer. Han blir klar over at han har forsyndet seg mot en av psykoterapiens grunnregler - han var gått $i$ den farligste felle for en sjelelege: Han hadde forelsket seg i sin egen pasient.

Bugge oppklarer saken og redegjør for vennene om hvordan hver nevrose har sitt skjulte mønster. Det er det man som sjelelege må prøve å få øye på. Han leser fra eventyret om Snehvit og påviser parallellene til hendelsesforløpet i Skjult mønster. Irene identifiserer seg med den stakkars forfulgte Snehvit, som til slutt får oppreisning samtidig med at den onde stemoren får sin rettferdige straff. Alt følger hennes ubevisste program. Snehvits stemor blir til slutt plantet i glødende jerntøfler, og hun må danse til hun segner død om på gulvet.

Det nye elementet i Skjult mønster er henvisningen til eventyrenes symbolkraft og at dette kan brukes suggestivt og $i$ ond hensikt. Det er Irenes tante som er den største skurken i dette eventyret, men det fremgår ikke om hun får sin straff.

\section{Essayer om psykoanalysen}

Bernhard Borge og Kai Bugge forsvinner ut av André Bjerkes forfatterskap fra 1950. Imidlertid befatter han seg fortsatt med psykoanalysen, spesielt $i$ to lengre essayer, som viser en økende skepsis til psykoanalysen som livsanskuelse.

I essayet Erindringer om fremtiden fra 1953, som er et oppgjør med determinismen (5), skriver André Bjerke bl.a. om den «deterministiske» roman: «Den viktigste variant av denne litteratur har vi i den psykologiske roman, slik den dominerte i mellomkrigstiden, inspirert av Sigmund Freuds forskningsresultater. Psykoanalysen var i første rekke en vitenskapelig begrunnet polemikk mot den victorianske moraloppfatning. Det er all grunn til å ære Freud for hans kulturelle renovasjonsvirksomhet; han har besørget vår tids mest omfattende søppelforbrenning. Men svikten i hans menneskesyn føler man tydelig i et essay som «Dostojevsky und die Vatertötung». 
Med stor skarpsindighet oppsporer Freud fadermord-komplekset i dikterens fantasiverden, avdekker det som årsaken til hans epilepsi og spillegalskap, hans desperate opprør mot autoriteter, og hans trang til forsoning med farssymbolene: tsaren og den gresk-katolske kirken. Man kan akseptere denne forklaring helt eller delvis; man kan medgi at det er dette som har gitt stoffet til Dostojevskis forfatterskap - og allikevel vil man stå helt uforstående overfor det faktum at denne nevrotiker frembragte genial kunst. Det er tross alt en vesensforskjell på et dikterverk og et epileptisk anfall! Det skapende i mennesket unndrar seg sjelekirurgens kniv» $(5$, s. 177-8).

Kanskje kunstneren $m a ̊$ være nevrotiker for å kunne skape kunst? I Skjult mønster diskuterer vennene dikterkunsten i psykoanalytisk perspektiv, og en av dem fyrer av følgende bredside mot psykologistudenten Jørgen etter at han under henvisning til Freud har hevdet at alle dikt må betraktes som nevrotiske manifestasjoner: ««Psykoanalysen», sier vennen, «er læren om hvordan man avskaffer sjelelivet - den dreper alle mysterier; den «tyder» eventyret ut av tilværelsen. En verden uten nevroser vil ganske riktig bli en verden uten diktning. Skjønner du ikke at disse diktene er gode nettopp fordi de er skrevet av en syk? Analysér ham «frisk», og du vil få en kjernesunn frisksportidiot som spiser Kruska og avler 12 barn og aldri mer skriver et dikt. Tenk for en fotballspiller Olaf Bull kunne blitt, om han var kommet til Freud i tide! Dere psykoanalytikere drømmer om et samfunn av konfliktfrie mennesker - en redselsfull tanke. Jeg akter i hvert fall å melde meg ut av den fotballklubben. Jeg sier: gud skje lov at det ennu finnes nevroserog følgelig også diktere» (4, s. 90-1).

\section{Arthur Koestler}

I 1955 skrev André Bjerke essayet Arthur Koestler og radikalismen, der han tydelig slutter seg til Koestlers (1905-83) kritikk av psykoanalysens reduksjonistiske tenkemåte, spesielt knyttet til temaer som etikk, moral og den frie vilje (6).

Koestler var en meget toneangivende tenker og skribent, ikke minst for den norske intelligentsiaen i 1940- og 50-årene, men er merkelig glemt i dag. Tidsskriftet har imidlertid nylig bidratt til å trekke ham frem fra glemselen (9).

Jeg har hatt stor glede av gjensynet med flere av bøkene hans, først og fremst hans spennende tobinds selvbiografi En pil $i$ det blå og Den usynlige skrift $(11,12)$, men også essaysamlingen Yogien og kommissceren og romanen Ankomst og avreise, som omhandler hans oppgjør med psykoanalysen $(13,14)$. Mest kjent ble han kanskje

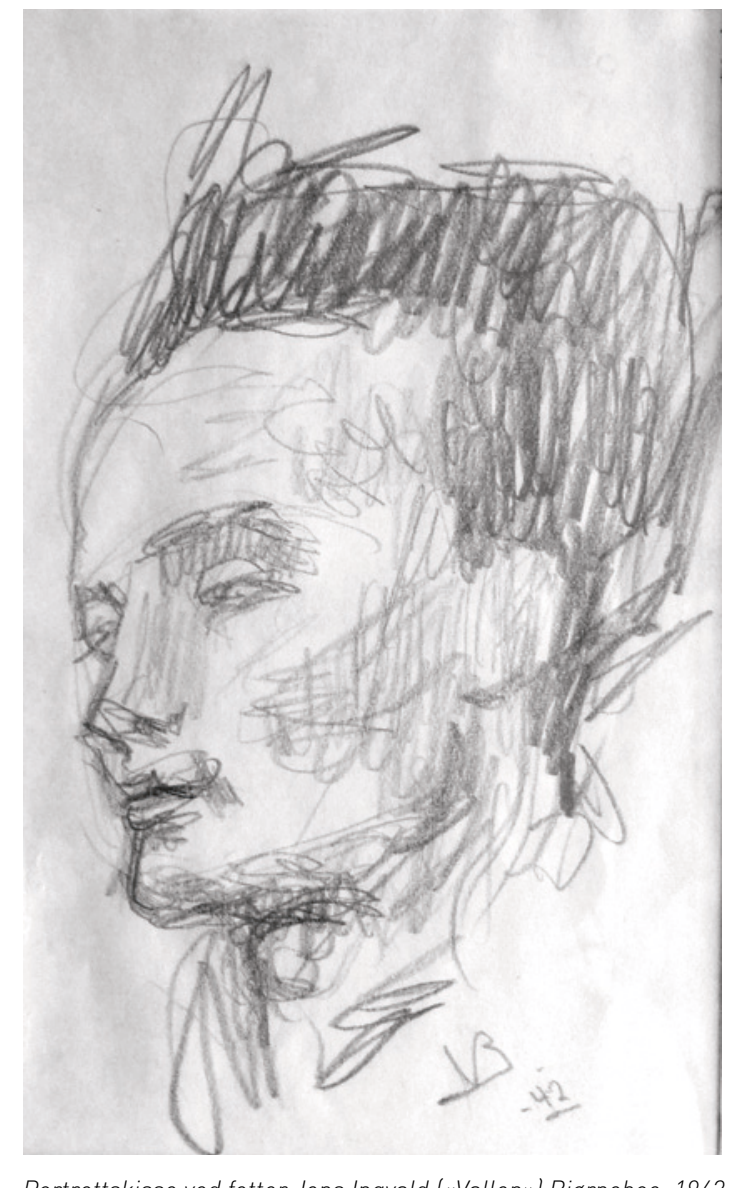

Portrettskisse ved fetter Jens Ingvald («Vallen») Bjørneboe, 1942

for sitt oppgjør med stalinismen i romanen Mørke midt på dagen (15), men jeg synes andre sider av hans forfatterskap er atskillig mer interessante.

Han korresponderte med flere fremtredende norske forfattere, bl.a. Jens Bjørneboe (1920-76) og Sigurd Hoel (1890-1960). Trygve Braatøy (1904-53) skrev i 1947 et langt essay, Arthur Koestler og psykoanalysen, som er en kritisk gjennomgang av Koestlers syn på psykoanalysen slik det fremkommer i Ankomst og avreise og Yogien og kommissceren (16).

André Bjerke skriver om Koestlers litteraere stil: «Denne pedagogiske stilkunst skulle jeg tro han har lært av Freud. En del av hemmeligheten ved psykoanalysens suksess er utvilsomt av rent stilistisk natur. Freud hadde nettopp denne evne til å åpne dørene i sin tankebygning med et fåtall magiske ordnøkler: «Ødipuskompleks», «lystprinsipp», «fortrengning», «oseanfølelse» - faktisk rene stilfunn» $(5$, s. 61$)$.

Deretter sammenfatter André Bjerke Sigmund Freuds beskrivelse av de tre store krenkelser mot menneskenes egenkjærlighet, begått av henholdsvis Kopernikus, Darwin og Freud, slik: «På en klode som bare er et fnugg bor et vesen som bare er et dyr, med en bevissthet som bare er reflekser av noe ubevisst. Her har vi innsirklet nøkkelordet i all radikal livsanskuelse: det er adverbiet bare. Dette er nemlig den radikale synsvinkel: Alt er noe annet og ringere enn det later til å være. Ateisten sier: religionen er bare overtro. Marxisten sier: individet er bare et produkt av sin samfunnsklasse. Freudianeren sier: åndsverket er bare en manifestasjon av en nevrotisk konflikt. I sin urform kommer den radikale holdning til uttrykk hos ynglingen som konstaterer: Fatter'n er bare en tufs! (...) Dette ene adverbiet var det som sprengte middelalderens verdensbilde. Dette bare har i fem hundre år ligget til grunn for nær sagt hver eneste vitenskapelige teori. Man har bedømt fenomener på et høyere organisasjonstrinn ut fra de lover som gjelder på lavere trinn. Man har redusert den moralske prosess til noe psykologisk, den sjelelige prosess til noe biologisk, den biologiske prosess til kjemi» (5, s. 70-71).

André Bjerke refererer så fra Koestlers beskrivelse av sitt første og eneste møte med Sigmund Freud, i London høsten 1938. Etter at Koestler har sagt noe om nazistenes misgjerninger skal Freud ha svart: «Nå ja, De vet, de avreagerer de aggresjonslystene 
som er oppdemmet $\mathrm{i}$ vår sivilisasjon. Det var ikke til å unngå at vi fikk noe slikt som dette, før eller siden. Sett fra mitt synspunkt er jeg ikke så sikker på at jeg kan kritisere dem» (12, s. 419).

Koestler kommenterer dette med at Freud her bare hadde gitt et konsekvent uttrykk for den etiske nøytralitet som det freudske system innebærer - og som er felles for all strengt deterministisk vitenskap. Når den vitenskapelige tenkning ut fra sine egne forutsetninger må forholde seg «etisk nøytral» til et fenomen som f.eks. nazismen, da må det være noe i veien med denne tenkningen, mener Koestler.

André Bjerke fortsetter så å beskrive Koestlers syn på psykoanalysen, om at det nettopp er den «nøytrale» moralfilosofi som er psykoanalysens akilleshæl: «Han (Koestler) beundrer det freudske SherlockHolmes-blikk for sjelens kriminalmysterier; han aksepterer oppklaringsmetoden og terapiens effektivitet - men han godtar ikke freudianerens manglende evne til å rødme. Han avviser det menneskesyn psykoanalysen gir uttrykk for. Den nøyer seg jo ikke med å være en medisinsk teknikk med en begrenset klinisk oppgave. Den pretenderer også å sitte inne med nøklene til alle menneskelivets hemmeligheter, enten de nå ytrer seg i religion, kunst og vitenskap eller $i$ en tilfeldig forsnakkelse, en drøm, en vits. Det er et av de store radikale forsøk på å skape en universell virkelighetsoppfatning, et altomspennende filosofisk system. Og innen dette system blir det moralske valg uttømmende forklart som et psykologisk determinert fenomen; hele det etiske kompleks blir løst opp i sine infantile og nevrotiske komponenter» $(5$, s. $75-6)$.

I Ankomst og avreise (15) behandles hovedpersonen for et såkalt korsfarersyn- drom. Behandlingen er tilsynelatende vellykket, konversjonssymptomene forsvinner, men så viser det seg at den helbredede pasienten slett ikke er blitt «tømt for moralsk innhold». «Etter å være befridd for den determinerende tvang av fortiden,» kommenterer André Bjerke, «er han ikke kommet ut av det moralske rom; tvert i mot er han for alvor kommet inn i det! Først nå opplever han det moralske som en egen lovmessig virkelighet. (...) Det moralske er ikke determinert av fortiden; det er et rom hvor det ustanselig skapes ny fremtid gjennom menneskets frie valg. Hovedpersonen gjør nå i frihet en moralsk handling: Han velger å reise til England for å melde seg til flystyrken og fortsette kampen mot nazismen. Han følger ikke «sunn fornuft» og «realitetsprinsippet» (...) han underordner seg nå det han vet er den hemmelige bestemmelse i hans skjebne: korsfarermotivet» $(5$, s. 83$)$.

\section{Avslutning}

Etter 1955 kan jeg ikke se at André Bjerke direkte befatter seg med psykoanalysen. Han blir mer opptatt av parapsykologi og okkulte fenomener, pussig nok i likhet med både Freud og Koestler og til en viss grad også Harald Schjelderup her hjemme (8).

For egen del var jeg i studietiden meg meget bevisst at jeg heldigvis var i ferd med å stake ut min egen kurs, langt unna fars fotspor. Men så oppdaget jeg plutselig, etter fullført psykoanalytisk utdanning, at jeg i stedet hadde havnet i sporene til detektivhelten i min fars kriminalromaner!

Artikkelen er en omarbeidet og forkortet versjon av foredrag holdt i flere fora, sist julemøtet ved Institutt for psykoterapi, desember 2012.

\section{Espen Bjerke (f. 1947)}

er spesialist i psykiatri, utdannet psykoanalytiker og arbeider som psykoterapiveileder og forsker ved Sykehuset Østfold Fredrikstad. Forfatter har fylt ut ICMJE-skjemaet og oppgir ingen interessekonflikter.

Litteratur

1. Bjerke A. Spillet i mitt liv. En amatør ved sjakkbrettet. Oslo: Aschehoug, 1968. Ny utvidet og revidert utgave: Aschehoug, 1975.

2. Borge B. Nattmennesket. Oslo: Aschehoug, 1941.

3. Borge B. De dødes tjern. Oslo: Aschehoug, 1942

4. Borge B. Skjult mønster. Oslo: Aschehoug, 1950.

5. Bjerke A. Erindringer om fremtiden. I: Bjerke A. Fuglen i fikserbildet. Oslo: Aschehoug, 1955.

6. Bjerke A. Arthur Koestler og radikalismen. I: Bjerke A. Fuglen i fikserbildet. Oslo: Aschehoug, 1955

7. Borge B. Døde menn går i land. Oslo: Aschehoug. 1947

8. Bjerke E. Sigmund Freud og Harald Schjelderup synspunkter på telepati og parapsykologi. Tidsskr Nor Lægeforen 2000; 120: 3775-8.

9. Borge B. Skjult mønster. Volum 60, Den Svarte serie. Oslo: Gyldendal, 1974

10. Engelsen BA. Arthur Koestlers nevrolitterære arv Tidsskr Nor Legeforen 2012; 132: 2626-9.

11. Koestler A. En pil i det blå. Oslo: Gyldendal, 1953.

12. Koestler A. Den usynlige skrift. Oslo: Gyldendal, 1954

13. Koestler A. Yogien og kommissæren. Oslo: Gyldendal, 1946.

14. Koestler A. Ankomst og avreise. Oslo: Gyldendal, 1946

15. Koestler A. Mørke midt på dagen. Oslo: Gyldendal, 1948

16. Braatøy T. Arthur Koestler og psykoanalysen. Oslo,

Mottatt 21.12. 2012, første revisjon innsendt 27.3. 2013, godkjent 26.4. 2013. Medisinsk redaktør Are Brean. 